\title{
A Audiência Pública da Saúde: questões para a judicialização e para a gestão de saúde no Brasil
}

\author{
Felipe Rangel de Souza Machado \\ Fundação Oswaldo Cruz \\ Sulamis Dain \\ Universidade do Estado do Rio de Janeiro
}

\begin{abstract}
O termo judicialização vem sendo utilizado nos países para nomear os mais diversos fenômenos que se diferenciam quanto à intensidade, profundidade e historicidade. A recente inserção do Poder Judiciário no campo da saúde no Brasil pode ser percebida como uma forma de "judicialização da política". O termo, entretanto, carece de uma definição mais clara, que permita identificar mais precisamente a profundidade desse fenômeno no Brasil. Nos últimos anos, observou-se no Brasil um aumento vultoso do número de ações judiciais voltadas para a garantia do direito à saúde. Isso implicou, entre outras cosias, uma apropriação rápida dos gestores da saúde da expressão "judicialização da saúde". Muitas das ações da área da saúde têm chegado à instância máxima do Judiciário brasileiro. A fim de refletir sobre essas ações, o Supremo Tribunal Federal (STF) convocou uma Audiência Pública (AP) para ouvir de toda a sociedade questões relacionadas ao direito à saúde. Cinquenta pessoas tiveram a oportunidade de se pronunciar nessa audiência. Assim, com base na análise da retórica, este estudo observa as falas desses oradores, buscando compreender o posicionamento perante o fenômeno da judicialização, os principais argumentos utilizados e as consequências para a gestão em saúde.
\end{abstract}

Palavras-chave: judicialização; direito à saúde; Poder Judiciário; políticas de saúde.

La Audiencia Pública de la Salud: cuestiones para la judicialización y para la gestión de la salud en Brasil

El término judicialización viene siendo utilizado en los países para nombrar los más diversos fenómenos que se diferencian en cuanto a la intensidad, profundidad e historicidad. La reciente inserción del Poder Judicial en el campo de la salud en Brasil puede ser percibida como una forma de "judicialización de la política". El término, sin embargo, carece de una definición más clara, que permita identificar más precisamente la profundidad de este fenómeno en Brasil. En los últimos anos, se observó en Brasil un

Artigo recebido em 25 maio 2011 e aceito em 12 abr. 2012. Este trabalho contou com o apoio da Fundação de Amparo à Pesquisa do Estado do Rio de Janeiro (Faperj) pelo Edital de Auxílio Instalação e constitui-se como desdobramento da tese de doutorado intitulada A judicialização da saúde no Brasil: cidadanias e assimetrias, defendida no Instituto de Medicina Social da Universidade do Estado do Rio de Janeiro (IMS/Uerj) sob orientação da professora Sulamis Dain. 
gran aumento del número de acciones judiciales dirigidas a la garantía del derecho a la salud. Esto trajo como consecuencia, entre otras cosas, una apropiación rápida de los gestores de la salud de la expresión "judicialización de la salud". Muchas de las acciones del área de la salud han llegado a la instancia máxima del Judicial brasileño. A fin de reflexionar sobre esas acciones, el Supremo Tribunal Federal (STF) convocó a una Audiencia Pública para escuchar de toda la sociedad las cuestiones relacionadas con el derecho a la salud. Cincuenta personas tuvieron la oportunidad de pronunciarse en esta audiencia. De este modo, con base en el análisis de la retórica, este estudio observa las fallas de estos oradores, buscando comprender el posicionamiento frente al fenómeno de la judicialización, los principales argumentos utilizados y las consecuencias para la gestión en salud.

Palabras clave: judicialización; derecho a la salud; Poder Judicial; políticas de salud.

Health Public Hearing: issues for the judicialization and to health management in Brazil

Judicialization has been in use on several countries as a term to define various phenomena according to their intensity and historicity. Recently, the Judiciary Power has addressed health issues in Brazil, a form of "policy judicialization". The term, however, lacks the precise definitions that would enable a deeper analysis of this phenomenon's range in Brazil. The last years have seen a significant increase on judicial actions aimed at guaranteeing health rights. Among its consequences, this led to a quick assimilation by health administrators of the term "health judicialization". Many health related judicial actions have arrived at the highest level of Brazil's Legal System. This has led the Supreme Court to create a Public Hearing to address civil society's issues regarding health rights, where fifty people were heard. This research analyses the rhetoric observed on these speakers' main arguments to understand their opinion regarding the judicialization phenomenon, and the main consequences to health administration.

Key words: judicialization; right to health; Judicial Power; health policy.

\section{Introdução}

Recentemente, temos nos deparado no Brasil com a crescente expansão do papel do Poder Judiciário em relação às políticas públicas, fenômeno já identificado há algumas décadas em diversos regimes democráticos. Esse processo de judicialização, tal como ficou reconhecido a partir de trabalhos de Tate e Vallinder (1995), envolve essencialmente tomar algo, no caso, as políticas públicas, sob a forma do processo jurídico. Hirschl (2006:726) afirma que a judicialização da política serve como um termo guarda-chuva que congrega fenômenos distintos, porém inter-relacionados.

Mesmo sendo um fenômeno típico dos séculos XX e XXI, é possível identificarmos alguns traços do que hoje denominamos judicialização ainda no século XIX. De acordo com Tocqueville (1987), por exemplo, dificilmente nos EUA uma questão política não era transformada, mais cedo ou mais tarde, numa questão judicial.

Não há ocorrência política para a qual não ouça ele [o estrangeiro] ser chamada a autoridade do juiz; e conclui, à vista disso, naturalmente, que o juiz é, nos Estados Unidos, uma das primeiras 
forças políticas. Depois, quando passa a examinar a constituição dos tribunais, só descobre nela, a princípio, atribuições e hábitos judiciários. Aos seus olhos, o magistrado nunca parece introduzir-se nos negócios públicos, a não ser por acaso, mas este mesmo acaso repete-se todos os dias (Tocqueville, 1987:82).

Mesmo se referindo a uma realidade do século XIX, as palavras do pensador e político francês parecem nos esclarecer um pouco as práticas atuais, e não apenas nos EUA. Mesmo no Brasil é possível perceber a força política crescente do Poder Judiciário. Não é incomum acompanharmos pela imprensa importantes decisões judiciais sobre questões políticas que afetam diretamente a vida de milhões de cidadãos.

A constituição do estado democrático moderno, de fato, tem na forma jurídica um de seus mais importantes pilares, pois é na linguagem específica desse campo, a partir da enunciação de leis, que muitas decisões políticas são expressas. O Judiciário, na tipologia weberiana da dominação racional-legal que caracteriza os Estados modernos (Weber, 2004), se alicerça na interpretação de normas, cuja função precípua é a tomada de decisões sobre a conformidade, a regularização e a aplicação dos códigos legais. Nesse sentido, embora o Judiciário, no modelo clássico da tripartição dos poderes, constitua um campo relativamente autônomo, com atribuições específicas, o direito mesmo é uma criação do Legislativo (constituição, códigos e leis) e, em alguns casos, do próprio Executivo (decretos, normas e portarias). A partir do final do século XX, sobretudo a partir do desmonte dos regimes de welfare, que trouxeram para suas constituições a garantia de direitos difusos e coletivos e o enfraquecimento dos atores coletivos outrora responsáveis por sua conquista, as fronteiras que separavam o Poder Judiciário dos demais poderes tornaram-se cada vez menos nítidas, na medida em que se intensificou a demanda pela garantia de direitos sociais, não tanto em manifestações abertas em ruas e praças públicas, mas nos limites estreitos dos tribunais.

No caso brasileiro, esse processo é bem mais recente, inicia-se na década de 1990, após o período de abertura democrática dos anos 1980 e no bojo do processo de reestruturação neoliberal do Estado. Além do evidente refluxo de muitos movimentos sociais que levaram à consolidação constitucional de diversas demandas sociais, entre as quais o direito à saúde, um dos fatores que muito contribuiu para impulsionar a maior atuação do Poder Judiciário no processo de definição das políticas públicas é o fato de a Constituição brasileira ser um documento repleto de normas indeterminadas, abertas a variadas interpretações.

O consenso possível estabelecido no momento da Assembleia Nacional Constituinte (ANC) implicou a criação de leis amplas e, por vezes, vagas. Vianna e colaboradores (1999) ressaltam que a ANC se desenvolveu sob uma forte tensão entre grupos antagônicos que disputavam a inscrição de sua hegemonia no texto constitucional. Dessa maneira, "deixava-se para o futuro a concretização dos valores e princípios positivados na Carta, na dependência do novo arranjo de forças subsequente ao processo democrático que a própria Constituição deveria inaugurar" (Vianna et al., 1999:41). 
Os autores argumentam ainda que, nesta disputa hegemônica no interior da ANC, havia duas expectativas distintas. Uma acreditava que, assim como acontecera com a Constituição de 1946, a nova Carta teria um significado meramente simbólico. Outro grupo de parlamentares constituintes apostava no papel que uma nova comunidade de intérpretes poderia vir a representar no controle abstrato das normas. O resultado da promulgação de nossa Carta Magna acompanhou a seguinte equação: quanto mais indeterminada for a Constituição, maiores serão os conflitos pela interpretação hegemônica entre os gestores das três esferas da federação, e maior será a discricionariedade do Poder Judiciário.

Esse novo papel atribuído ao Judiciário significou uma inevitável ampliação de sua atuação, processo esse que vem sendo denominado, como aludimos, judicialização. Conforme acepção de Taylor (2007:248), o Poder Judiciário desempenha um papel central no processo político, pois

decide quais regras são legítimas e estão em concordância com as leis locais ou a Constituição, assim como quais ações (ou omissões) representam aberrações ou infrações. Como resultado, os tribunais influenciam o curso das políticas públicas: tribunais e juízes influenciam o tipo de políticas que são implementadas e julgam a legalidade dessas políticas dentro da sua visão das regras legais existentes e das normas e tradições vigentes.

Decorrente da referida abertura constitucional, no Brasil, assume-se que a responsabilidade pela maioria dos serviços públicos é comum aos três níveis da federação, o que acaba gerando debates sobre as responsabilidades de cada nível. Oliveira (2009) ressaltou o papel fundamental do STF como árbitro de muitos desses conflitos, apontando que o governo central em geral é favorecido. Tal atuação também pode ser considerada um caso de judicialização.

No cenário acadêmico brasileiro, o termo judicialização foi apropriado inicialmente pelos estudos de Vianna e colaboradores (1999), na obra Judicialização da política e das relações sociais no Brasil, na qual se discute a judicialização a partir de dois eixos interpretativos. No primeiro deles, o eixo procedimentalista, se percebe uma diminuição da cidadania, "a judicialização da sociedade desinstitucionalizaria a democracia, marginalizando as instituições de mediação — as associações e os partidos políticos" (Vianna et al., 1999:26). Nesse eixo interpretativo, assume-se que a concepção de justiça é da autonomia e não do bem-estar. Dessa forma, os cidadãos "teriam que se reconhecer como autores no seu direito, e não como seus destinatários" (Vianna et al., 1999:26). Além disso, a única forma de se garantir a igualdade entre os cidadãos seria pela ampliação dos canais de formação da vontade majoritária, o que ocorreria pelo permanente aperfeiçoamento dos procedimentos democráticos.

No segundo eixo, o substancialista, a judicialização é tratada como uma extensão da democracia e uma ampliação da cidadania. Assim, "o Poder Judiciário pode contribuir para o aumento da capacidade de incorporação do sistema político, garantindo a grupos marginais, destituídos de meios para acessar os poderes políticos, uma oportunidade para a vocalização de suas expectativas de direito" (Cappelletti, 1993:34). Numa perspectiva mais ampla, “a 
política se judicializa a fim de viabilizar o encontro da comunidade com os seus propósitos, declarados formalmente na Constituição" (Vianna et al, 1999:40).

Dessa forma, a cidadania política permitiria a participação dos cidadãos nos procedimentos democráticos que levam à formulação da lei e forneceria a esses cidadãos a possibilidade de reivindicar judicialmente a aplicação da lei. No caso brasileiro, isso se verifica, por exemplo, a partir das instituições da Ação Civil Pública (ACP), das Ações Diretas de Inconstitucionalidade (Adin) e do Mandado de Segurança (com pedido de liminar). Este último tem sido recorrentemente utilizado na área da saúde, processo que vem sendo denominado de judicialização da saúde. Ou seja, busca-se nos tribunais a garantia de um direito reconhecido constitucionalmente.

A estratégia dos sujeitos de garantirem seus direitos recorrendo ao Poder Judiciário tem acontecido, sobretudo, em duas dimensões distintas. A primeira delas representa os interesses individuais, inserindo-se nesse campo a Defensoria Pública e os escritórios privados de advocacia. Suas demandas dizem respeito aos direitos que os indivíduos acreditam que o Estado deveria garantir e, geralmente, relacionam-se à compra de determinados insumos necessários à manutenção ou à recuperação da saúde dos indivíduos. A segunda dimensão representa os interesses coletivos, em geral defendidos por associações da sociedade e pelo Ministério Público, que buscam a garantia de acesso a insumos e serviços para a coletividade.

Ressalta-se que a receptividade do Poder Judiciário em relação às ações demandando direitos individuais ou direitos coletivos tem-se mostrado diversa. Em geral, obtêm-se mais resultados em pleitos individuais, nos quais o processo diz respeito à compra de um insumo específico ou ao pagamento de um procedimento médico-hospitalar, fato que tem dado mais notoriedade ao processo de judicialização da saúde no Brasil. O Poder Judiciário tem evitado opinar sobre os casos considerados coletivos na área da saúde, possivelmente porque tais ações incidem diretamente na condução das políticas públicas para o setor, além de requererem maior gasto público.

Essa nova forma de luta pela conquista de direito no campo da saúde vem ocorrendo porque o conteúdo das leis no campo é amplo e geralmente indeterminado, a exemplo da polêmica discussão a respeito da inserção, no gasto da saúde, de medidas de combate à fome. A grande abertura que compõe o texto da saúde na Constituição de 1988 criou no Brasil um duplo movimento. Se os conceitos jurídicos indeterminados eram insuficientes para garantir a oferta de bens e serviços de saúde para a população brasileira, num momento seguinte, essa mesma indeterminação foi usada como artifício para a garantia do direito à saúde. Neste meio-tempo, é nítida a mudança de postura do Poder Judiciário, que deixou de ser uma tímida instituição para assumir um papel de destaque no setor de saúde. Exemplo marcante foi a postura do Judiciário em relação aos medicamentos antirretrovirais (Gouvêa, 2003).

Como defendem Ventura e colaboradores (2010), os estudos da judicialização na área da saúde vêm sendo feitos em duas direções. Numa delas são enfatizados "mais fortemente os efeitos negativos deste tipo de demanda na governabilidade e gestão das políticas e ações de saúde"; em outra são apontadas "as deficiências e insuficiências do sistema de saúde e do 
sistema judiciário brasileiro para responder de forma satisfatória às novas e crescentes demandas de saúde" (Ventura et al., 2010:79).

Independentemente do tipo de análise empreendida, é unânime no campo da saúde a observação do aumento vultoso nos últimos anos do número de ações judiciais voltadas para a garantia do direito à saúde. Muitas dessas ações têm chegado à instância máxima do Judiciário brasileiro, na medida em que o setor público recorre das decisões impostas pelos magistrados. A fim de refletir sobre essas ações, o ministro do STF, Gilmar Mendes, convocou uma Audiência Pública (AP) para ouvir, de toda a sociedade, questões relacionadas ao direito à saúde. O próprio ministro reconhece a relevância do tema, dada a crescente demanda que chega ao STF para análise de pedidos de suspensão de segurança, suspensão de liminar e suspensão de tutela antecipada de competência da Presidência.

No pronunciamento de abertura, o ministro Gilmar Mendes esclarece que a AP "foi convocada para ouvir o depoimento de pessoas com experiência e autoridade em matéria de Sistema Único de Saúde (SUS). A Audiência objetiva esclarecer as questões técnicas, científicas, administrativas, políticas e econômicas envolvidas nas decisões judiciais sobre saúde". Além disso, justifica o ministro:

Por estar relacionada aos vários pedidos de suspensão que tratam da matéria, esta Audiência Pública distingue-se das demais pela amplitude do tema em debate. Todos nós, em certa medida, somos afetados pelas decisões judiciais que buscam a efetivação do direito à saúde. O fato é que a judicialização do direito à saúde ganhou tamanha importância teórica e prática que envolve não apenas os operadores do direito, mas também os gestores públicos, os profissionais da área de saúde e a sociedade civil como um todo.

A AP contou com a fala de 50 pessoas que se dedicaram durante seis dias a discutir as questões relativas à saúde no Brasil. Dada a importância dessa audiência para os rumos que pode tomar o padrão decisório do STF em relação aos casos da saúde, e seu consequente impacto sobre a gestão do setor saúde no Brasil, este artigo tem o objetivo de analisar estas falas públicas, visando identificar, no discurso de cada participante, os principais argumentos relacionados ao fenômeno da judicialização no Brasil.

\section{Métodos e técnicas}

Realizou-se um estudo exploratório e qualitativo, utilizando-se a "análise de retórica" (Perelman e Olbrechts-Tyteca, 1996) como instrumento de compreensão do amplo material disponível. Para estes autores (Perelman e Olbrechts-Tyteca, 1996:6), "é em função de um auditório que qualquer argumentação se desenvolve", ou seja, interessa investigar a estrutura do discurso que é proferido em público. Dessa forma, foi interessante identificar que estratégias cada orador utilizava para convencer não só o ministro do Supremo, mas toda a plateia presente na AP. Além disso, esses autores defendem que a argumentação jurídica é um gênero 
próprio e específico, ele "se refere a avaliações sobre a natureza e a causa de eventos passados, em que diversas estratégias de convencimento são utilizadas" (Perelman e Olbrechts-Tyteca, 1996:53). Contudo, apesar de ser próprio do Poder Judiciário esse olhar para o passado, não podemos perder de vista os efeitos práticos da argumentação desenvolvida na AP, "voltada para o futuro, ela se propõe provocar uma ação ou preparar para ela, atuando por meios discursivos sobre o espírito dos ouvintes" (Perelman e Olbrechts-Tyteca, 1996:53). Além disso, para os autores, o gênero judiciário é um caso privilegiado de análise, pois é possível conhecer de antemão as intenções dos sujeitos.

No processo judicial, sabemos que o advogado de cada parte tende menos a esclarecer-se do que a desenvolver argumentos em favor de uma tese. Fixando os pontos a serem debatidos, o direito favorece essa atitude unilateral, essas tomadas de posição, que o litigante só tem de sustentar com constância contra o seu adversário (Perelman e Olbrechts-Tyteca, 1996:43).

Isso significa que o argumento das partes tende a ser muito mais evidente na retórica jurídica. Ainda assim, é importante ressaltar que não é possível afirmar que a análise empreendida aqui se encontra nos estreitos limites da análise de retórica, mas essa foi a proposta teórica que orientou a análise das falas.

A análise baseou-se nas falas transcritas disponibilizadas pelo STF em seu portal (www. stf.jus.br). A primeira análise pertinente diz respeito à identificação dos sujeitos que prioritariamente defendem ou se contrapõem à judicialização da saúde. Certamente, não se imaginava encontrar argumentações puras, definidas estritamente como favoráveis ou contrárias à judicialização. Contudo, os sujeitos que se inscreveram para falar na referida audiência tinham como propósito se posicionar em relação a esse fenômeno. Por esse motivo, utilizamos o termo prioritário para identificar as retóricas prós ou contrárias a esse fenômeno.

\section{Análise do material empírico}

A APS teve um significado especial para o campo da saúde, pois representou o reconhecimento da instância máxima do Poder Judiciário de que a saúde passou a ser uma questão importante no cotidiano desse Poder. Esse tipo de procedimento adotado pelo STF favorece o exercício da cidadania com vistas a uma participação efetiva da sociedade nos rumos das decisões que têm caráter político e elevada abrangência. Justamente por servir como um auxílio teórico sobre a questão da saúde e um "termômetro social" sobre as diversas concepções em disputa, esta primeira APS contém em si elementos significativos para a análise política da judicialização.

Das 50 falas analisadas, foi possível observar em 41 delas algum posicionamento favorável ou contrário à judicialização. ${ }^{1}$ Conforme sugeriram Perelman e Olbrechts-Tyteca

\footnotetext{
${ }^{1}$ Ainda que pareça uma diferenciação maniqueísta, não se deve olvidar que o resultado da Audiência Pública pode ter um caráter normativo para os outros níveis do Judiciário. Mesmo que cada orador tenha medido suas palavras a ponto de não causar constrangimento à plateia, partiram de uma premissa básica: favorável ou contrária ao atual
} 
(1996:73), a análise da argumentação volta-se primeiro para o que é aceito como ponto de partida de raciocínios para, em seguida, debruçar-se na maneira pela qual os oradores desenvolvem seus raciocínios "graças a um conjunto de processos de ligação e de dissociação".

Entendemos por processos de ligação esquemas que aproximam elementos distintos e permitem estabelecer entre estes uma solidariedade que visa, seja estruturá-los, seja valorizá-los positiva ou negativamente um pelo outro. Entendemos por processos de dissociação técnicas de ruptura com objetivos de dissociar, de separar, de desunir elementos considerados um todo, ou pelo menos um conjunto solidário dentro de um mesmo sistema de pensamento (Perelman e Olbrechts-Tyteca, 1996:215).

Dessa forma, considerou-se o posicionamento de cada orador como a base de sua argumentação. Segundo Perelman e Olbrechts-Tyteca (1996:26), “o importante, na argumentação, não é saber o que o próprio orador considera verdadeiro ou probatório, mas qual é o parecer daqueles a quem ela se dirige”. Assim, após localizar cada orador em relação ao fenômeno da judicialização da saúde, apresentar-se-ão os principais argumentos utilizados para convencer o auditório.

Deve-se ressaltar, ainda, a importância que esses oradores têm no cenário público no que diz respeito à análise da judicialização da saúde. Eles representam grupos e instituições absolutamente interessados na redução, manutenção ou ampliação da atuação do Poder Judiciário no campo da saúde pública. Muitos dos oradores presentes, representantes da gestão do SUS, defendem uma mudança drástica no padrão decisório da Justiça brasileira; outros, no entanto, buscam, nessa audiência, fortalecer o papel que esse Poder vem desempenhando na garantia do direito à saúde no Brasil. A literatura tem demonstrado que a judicialização tem, entre seus diversos fatores determinantes, a busca de direitos por grupos minoritários e a falta de consenso político no interior do Poder Legislativo (Cappelletti, 1993; Tate e Vallinder, 1995). Essas duas temáticas permearam toda a discussão ocorrida nos seis dias de audiência.

No que diz respeito ao posicionamento dos participantes da AP, pode-se dizer que existe uma forte relação entre a inserção institucional e a posição que defendem. Numa breve aproximação, podem-se distribuir todos os oradores em três macrocategorias de inserção profissional: "gestores" (ou representantes da gestão dos serviços de saúde); "operadores do direito" e "participantes da sociedade civil". Primeiramente, deve-se dizer que a distribuição dos oradores entre essas três macrocategorias é bastante igualitária, o que facilita a comparação entre os grupos. Em segundo lugar, importa esclarecer que estas não são conclusões de base estatística, mesmo porque não há aqui o princípio da aleatoriedade na escolha da amostra. Como mencionado anteriormente, a participação nesta audiência ocorreu mediante

estágio de desenvolvimento do fenômeno da judicialização. Poderia ter-se adotado outra terminologia mais amena, mas decidiu-se por esse modelo justamente para enfatizar o tipo de influência que cada orador pretendeu ter sobre a percepção dos ministros do STF a respeito das demandas judiciais em saúde. 
inscrição de tese e aceite do ministro que convocou a atividade. Porém, mesmo diante dessas limitações, é possível perceber algumas relações importantes que corroboram certas hipóteses relacionadas ao fenômeno da judicialização.

Nesse sentido, ao atentar-se para a distribuição dos gestores entre os três posicionamentos, não se estranhou que a maior parte deles fosse contrária às demandas judiciais. Dos 15 gestores que tiveram direito à fala, nove foram contrários, dois favoráveis e quatro indeterminados. Esse posicionamento majoritário se explica pelo fato de os gestores analisarem as demandas judiciais em saúde pela ótica dos recursos escassos. Buscam, em suas falas, demonstrar que o gasto via determinação judicial desestabiliza as contas dos serviços de saúde e inviabiliza o planejamento e o desenvolvimento das ações coletivas em saúde. Além disso, destaca-se que a percepção dos gestores é de que, em geral, os juízes erram o destino das ações judiciais, não respeitam as divisões de atribuições entre os entes federados. Esse argumento, contestado pelos magistrados, se funda na própria forma em que o SUS se desenvolveu. Como afirma Trevisan (2007), o processo de descentralização do SUS aconteceu de forma muito acelerada, e apresentando uma insuficiência na negociação e pactuação entre os diversos atores do SUS. Essa indução com que o Ministério da Saúde operou a descentralização no Brasil contribui bastante hoje com parte das questões associadas à judicialização da saúde. O tema da descentralização, inclusive, constituiu um dos aspectos mais frequentes na argumentação desenvolvida na AP da saúde.

Pensamento oposto a esse é adotado pelos participantes da sociedade civil. Nesse grupo, encontram-se pacientes, representantes de associações de pacientes, médicos, pesquisadores, entre outros. Esse grupo, representado por 16 pessoas, teve apenas uma fala contrária e três indeterminadas, ficando amplamente concentrado na defesa das demandas judiciais. O fato de realizarem a defesa da judicialização deve-se, sobretudo, à percepção de que a Justiça tem auxiliado no alcance e na continuidade de tratamentos que, pelos trâmites do SUS, seriam impossíveis. Defende-se aqui o direito individual à saúde e à vida.

Os operadores do direito também ficaram bastante concentrados na defesa das demandas judiciais. Dos 19 oradores, 14 defenderam a importância da judicialização. Dos quatro contrários, três eram procuradores de estados ou municípios e o outro era advogado geral da União, ou seja, são pessoas que têm como função defender os interesses da gestão do Estado, portanto assumem posição similar à dos gestores. Apenas um não se posicionou claramente. Neste grupo de oradores, também não há surpresas quanto às posições que adotaram, mesmo porque são os próprios operadores do direito os principais responsáveis pelo fenômeno da judicialização. De um lado, os advogados buscam obter direitos para seus clientes; de outro, os magistrados aceitam a tarefa de julgar estes casos e, na maioria das vezes, acenam positivamente para eles.

Pode-se dizer que a AP da saúde dividiu-se em duas estratégias distintas, uma que defendia o "lugar da quantidade" e a outra, o "lugar do irreparável". "Entendemos por lugares da quantidade os lugares-comuns que afirmam que alguma coisa é melhor do que outra por razões quantitativas" (Perelman e Olbrechts-Tyteca, 1996:97). Dessa forma, o maior ataque contra as demandas judiciais em saúde ocorre pelo custo que ela impõe aos serviços de saúde, consumin- 
do grande quantidade de recursos para poucas pessoas, quando esses recursos poderiam ser utilizados para um conjunto maior de pessoas. Já “o lugar do irreparável se apresenta como um limite, que vem acentuar o lugar do precário: a força argumentativa, vinculada à sua evocação, pode ter um efeito fulminante" (Perelman e Olbrechts-Tyteca, 1996:103). Assim, em diversas ocasiões são levantados fatos de pessoas que morreram sem conseguir um medicamento ou de pessoas que podem morrer caso não obtenham um tratamento.

Além dessas estratégias retóricas, merece destaque a utilização, por ambos os lados, de "hierarquias" (Perelman e Olbrechts-Tyteca, 1996:90). Em relação ao exame da argumentação, esses autores admitem duas categorias: "uma relativa ao real, que comportaria os fatos, as verdades e as presunções, a outra relativa ao preferível, que conteria os valores, as hierarquias e os lugares do preferível" (Perelman e Olbrechts-Tyteca, 1996:74).

Observou-se que, na AP, a todo momento, são invocados argumentos que buscam hierarquizar as situações: o justo sobre o injusto, o todo sobre a parte, o mais barato sobre o oneroso. O que está em jogo aqui é a organização que se dá aos dados existentes sobre a judicialização da saúde. Convencer o auditório sobre uma dessas hierarquias é levá-lo a concordar com a premissa que as embasam. A evocação dessas hierarquias não ocorre, no entanto, apenas na retórica dos participantes, todas elas estão postas no cotidiano. Em determinados momentos, optou-se por uma ou por outra. Note-se que tais hierarquias não se constituem como antagônicas, mas nem por isso podem ser utilizadas em conjunto. Justamente pela proximidade que elas têm com a vida dos sujeitos que ouvem é que são importantes, cabendo ao orador articulá-las da melhor forma possível.

Por último, é importante destacar os "tipos de objetos de acordo" utilizados. Cada orador apresenta um leque de dados, fatos, verdades e presunções que são a base de seus posicionamentos. Assim, os oradores tentam, em suas retóricas, convencer o auditório de que a situação, na forma como ele apresenta, é a melhor maneira de ser interpretada. Não se pode perder de vista que o auditório pretendido constitui-se primordialmente dos ministros do Supremo. Esses, por sua vez, fazem parte de um corpo (o Poder Judiciário) que vem decidindo favoravelmente sobre as demandas judiciais em saúde. Dessa forma, além das estratégias citadas até agora, operou-se fundamentalmente uma hermenêutica do texto constitucional, sobretudo dos princípios e diretrizes do SUS.

\section{Os principais argumentos utilizados}

Os argumentos podem ser compreendidos como os meios utilizados pelos indivíduos para sustentar suas ideias a fim de persuadir ou convencer sua audiência. Interessante destacar que o mesmo tipo de argumento, por vezes, foi evocado ora para defesa, ora para ataque ao fenômeno da judicialização da saúde, como é o caso, por exemplo, de argumentos baseados no princípio da integralidade da saúde.

Pode-se dizer que, antes mesmo da adoção de premissas específicas, seja a favor ou contra o fenômeno da judicialização no campo da saúde, foi possível identificar pelo menos 
duas estruturas argumentativas às quais elas aderem: 1) estruturas argumentativas por princípio; 2) estruturas argumentativas pragmáticas. Em cada uma dessas estruturas, não necessariamente excludentes, podem-se encontrar argumentos favoráveis e contrários. A primeira diz respeito à formação de um juízo sobre casos particulares a partir de regras gerais ou de disposições jurídicas abstratas, que objetivam o convencimento pelo uso da razão. A segunda refere-se a avaliações concretas e valorativas tomando em consideração os casos particulares, independentemente de referências a normas abstratas, que muitas vezes pretendem atingir o convencimento pela empatia. Em geral (há exceções, evidentemente), notamos que a primeira matriz argumentativa tende a ser utilizada com mais frequência por representantes da área do direito; já a segunda matriz tende a ser evocada, principalmente, pelos representantes da gestão dos serviços de saúde e pelos representantes de associações de portadores de patologias.

Mesmo que não seja nossa intenção provar a existência do fenômeno da judicialização em si, cabe retomarmos algumas das premissas apresentadas por Tate e Vallinder (1995), as quais condicionam a ampliação do Poder Judiciário. Esses autores propõem que seja verificada a existência de oito premissas para que um dado fenômeno possa ser chamado de judicialização. Na análise da AP da saúde identificamos seis dessas premissas: 1) existência de uma política de direitos, inscrita ou não em uma declaração constitucional de direitos fundamentais; 2) existência de grupos de pressão que tenham identificado nos tribunais judiciais possíveis arenas para a veiculação de seus interesses; 3) existência de instituições majoritárias incapazes de reunir em torno de si apoio público suficiente para defender suas políticas, havendo, portanto, a necessidade de se buscar no Poder Judiciário a efetivação dessas políticas; 4) uma percepção geral negativa quanto às instituições originalmente responsáveis pela formulação de políticas públicas, trazendo esse sentimento negativo de receios públicos quanto a clientelismo, personalismo e corrupção; 5) inércia proposital do Legislativo quanto ao trato de certas questões (ou seja, falta de consenso político); e 6) uma postura dos juízes no sentido de aceitarem o desafio de opinar sobre questões políticas.

Em primeiro lugar, destaca-se a evocação recorrente à Carta Constitucional de 1988, trazendo para o campo da prática a existência teórica de uma política de direito à saúde, de forma a negar a perspectiva que esse direito assume como uma norma programática. A esse respeito, o representante do Conselho Federal da Ordem dos Advogados do Brasil (OAB) afirmou que o Brasil, desde a promulgação da Constituição de 1988, evoluiu em relação à eficácia dos direitos sociais. Além disso, enfatiza o atual momento de definição a respeito da amplitude do Poder Judiciário como garantidor desses direitos:

Momento este que se pode dizer um dos mais ricos da história do constitucionalismo brasileiro, pois, após compreender o sentido da Constituição Republicana de 1988, passamos a definir critérios não mais para negar-lhe eficácia, como há pouco faziam alguns autores, referindo-se a esses direitos como meras normas programáticas, mas discutindo uma dogmática constitucional capaz de atender aos conflitos decorrentes da práxis constitucional, sem em nenhum momento negar a eficácia desses direitos (Flávio Pansieri). 
Outro orador que abordou esse assunto foi o defensor público geral da União, doutor Leonardo Mattar, reforçando a tese de que considerar o direito à saúde como norma programática "cria descrédito e insegurança com relação às normas e ao próprio Estado brasileiro". Ao contrário disso, para ele, a afirmação do direito à saúde como um direito de plena eficácia fortalece o sentimento da população de pertencimento ao Estado brasileiro, "e não simplesmente sujeitos de deveres". O professor Ingo Sarlet seguiu a mesma linha argumentativa. Para ele, apenas a partir da década de 1990 é que o Judiciário abandonou uma postura mais

tímida em relação à judicialização da política e também em relação à própria efetividade do direito à saúde. Na verdade, até então, a posição dominante era, inclusive no Superior Tribunal de Justiça (STJ), de que o direito à saúde era norma programática e, portanto, não tinha aplicabilidade alguma, a não ser na medida da lei que o concretizasse (Ingo Sarlet).

Para esse orador,

Hoje mesmo, adeptos da judicialização reconhecem (...) que é necessário superar a era dos extremos, tanto a rejeição da mera programaticidade é necessária quanto também rejeitar e controlar o famoso "pediu-levou", não importa quem pediu, o que pediu, as consequências da decisão. A busca, portanto, de uma conciliação entre a dimensão subjetiva, individual e coletiva do direito à saúde e a dimensão objetiva da saúde como dever da sociedade e do Estado, e de como a judicialização deve ser sensível a ambas as dimensões (Ingo Sarlet).

A alusão explícita à ideia de norma programática não aconteceu em todas as falas, mas é possível associarmos parte dos argumentos proferidos com essa perspectiva teórica. Assim, as discussões a respeito dos princípios e das diretrizes do SUS trazem à tona divergências em relação às formas de efetivação do direito à saúde, ou, mais que isso, até mesmo sobre o próprio conceito de direito à saúde. Na tentativa de familiarizar o auditório com a tese a ser desenvolvida pelo orador (favorável ou contrária à judicialização), a quase totalidade dos oradores trouxe para o centro do debate as principais diretrizes e princípios do SUS. Em alguns casos, propôs-se, inclusive, uma reinterpretação destes princípios. Caso mais evidente ocorre com o princípio da integralidade, que, por assumir diversos sentidos, enseja interpretações diversas (Mattos, 2004).

Para um secretário estadual de Saúde "a integralidade corretamente interpretada no sistema de saúde racionaliza a oferta de serviços e, por isso, transforma-se em instrumento fundamental de melhoria da eficiência dos gastos". Um dos procuradores de Justiça busca justificar, pela própria lógica de estruturação do direito, que a integralidade tem alguns limites legais superiores, que seriam, para ele (no caso da assistência farmacêutica), a Anvisa e os protocolos clínicos do SUS. "A delimitação de critérios atendíveis eticamente de oferta não significa necessariamente a negação da diretriz da integralidade."

Em todos os trechos a respeito da interpretação do princípio da integralidade, fica evidente a intenção de restringir a integralidade àquilo que a gestão dos serviços e do sistema de- 
terminar como científica e eticamente viáveis. Significa dizer que um princípio constitucional seria regulado por normas infraconstitucionais, que, ademais, seriam produzidas por órgãos vinculados ao Poder Executivo e não ao Legislativo.

Ao contrário dessa perspectiva, um grupo de oradores assume o princípio da integralidade como algo necessariamente amplo e altamente aplicável à vida material. O representante do Grupo Hipupiara chega a afirmar que a AP que está sendo realizada tem o propósito de julgar se a integralidade é um conceito absoluto ou relativo, em outros termos, se a saúde é ou não uma norma programática. Esse orador articula argumentos voltados para a interpretação do texto constitucional (integralidade), para a defesa da dimensão individual à saúde e para a ênfase em alguns aspectos subjetivos, evidenciando o que Perelman e Olbrechts-Tyteca (1996) chamaram de "lugar do irreparável", pois as mortes dos pacientes não poderiam ser revistas, sendo necessária, portanto, a antecipação da tutela. O orador apresenta, neste sentido, fortes marcas de uma argumentação baseada na emoção, visando sensibilizar o auditório a partir da criação de uma empatia.

Finalizando, gostaria de rogar a Vossas Excelências, que irão julgar se o conceito de integralidade do SUS é absoluto ou relativo, que lembrem de minha mãe e de meu pai, que estão assistindo, repito, angustiados a esta transmissão. Peço, em nome deles, que não me condenem à morte, porque ainda não descobriram reversão para o fenômeno de resistência viral. Muito em breve eu deverei necessitar de mais um medicamento aprovado internacionalmente, porém não incluído na lista do SUS. (...) Não tenho dúvidas, Excelências, que, no caso deste Tribunal considerar que o conceito de integralidade do SUS é relativo, esta Audiência será lembrada com bastante severidade, em todos os velórios. Esta Audiência será lembrada com bastante severidade em todos os sepultamentos de pessoas que faleceram por não obter do Estado a integralidade na assistência que os manteria vivos. Dentre eles, este que vos fala (Representante do Grupo Hipupiara).

A ideia de equidade foi também um argumento recorrente na fala dos oradores ao se referirem ao texto constitucional, sobretudo associando-a à noção de cidadania. Para alguns oradores, a judicialização da saúde gera dois tipos de cidadãos, os com liminar e os cidadãos que devem se submeter aos trâmites burocráticos e às filas do SUS. Outra perspectiva, mais pragmática, aponta para os resultados que as liminares têm tido, salvando vidas e garantindo o direito à vida também àqueles com doenças raras. Uma terceira interpretação da equidade defende que apenas os mais pobres teriam o direito de ingressar com ações na justiça, visando evitar que os mais favorecidos tenham acesso privilegiado "via liminar".

O princípio da universalidade, por sua vez, apareceu com mais frequência associado ao argumento do custo do tratamento e da segurança dos pacientes. O primeiro caso é mais evidente e aparece como o argumento mais frequente nesta audiência. Trata-se aqui de um típico exemplo de utilização do "lugar da quantidade", ou seja, o argumento enfatiza que um sistema que garante medicamentos caros para poucos à custa da exclusão de muitos não poderia ser considerado universal; argumento que, embora recorrente, poucas vezes foi rebatido. Em 
uma dessas ocasiões, uma procuradora do Distrito Federal apresentou a relação de gasto com medicamentos e com publicidade pelo governo do Distrito Federal, enfatizando a existência de um grande descompasso entre a definição de prioridades nesse governo.

A argumentação baseada na quantidade foi preponderante na fala dos representantes da gestão. Além disso, tentou-se, a partir da demonstração dos vultosos gastos realizados no setor saúde, associar a ideia de demanda judicial com a redução nas verbas da saúde para a maior parte da população. Para o representante do Conselho Federal de Medicina (CFM), no entanto, esse argumento tenta introduzir a ideia de que se deve sacrificar algumas vidas para salvar outras (em maior número). Para ele,

a seguir esse raciocínio ao pé da letra, não há justificativa para que o Estado invista no tratamento de pacientes acometidos por patologias como insuficiência renal crônica, por exemplo, que gasta vultosa quantia com hemodiálise, transplantes, medicamentos para beneficiar um pequeno grupo da sociedade. Ato contínuo, alguém propõe que se os deixe morrer, economizando-se esse recurso para um maior contingente populacional. Expõe-se aqui o lado mais cruel da visão utilitarista (Representante do CFM).

Observa-se que a ideia de que o custo do tratamento demandado via justiça impede a manutenção do princípio da universalidade assumiu o centro dos debates no decorrer da AP. Os dados fornecidos pelos oradores muitas vezes foram apresentados isoladamente, sem a sua devida contextualização e, sobretudo, sem a comparação com o todo. Dessa forma, muitos gestores se limitaram a apresentar os dados financeiros, como se suas conclusões pudessem ser inferidas disso espontaneamente; argumento que se encerra em si mesmo, participando do repertório dos "tipos de objetos de acordo" usados para demonstrar à plateia que a melhor maneira de se encarar os fatos é pelo "lugar da quantidade".

Uma terceira configuração da universalidade, embora menos comum, merece destaque. Ela versa sobre a importância do direito à saúde não se transformar em direito ao consumo de medicamentos. Conforme expressou o representante da Associação Nacional do Ministério Público de Defesa da Saúde (Ampasa), "a lógica sanitária é pública e não privada. A saúde não é e nem poderá ser tratada como uma mercadoria; isto muito menos pelo próprio Estado brasileiro. O titular do direito à saúde é um cidadão e não um consumidor". Para esse orador, isso significa reconhecer que, "quando se fala em universalidade, fala-se em universalidade da cidadania e não universalidade do consumo. Fala-se em universalidade da saúde e não em universalidade da mercadoria".

O princípio do SUS mais lembrado foi o da descentralização, com seus desdobramentos em hierarquização e regionalização. Uma primeira acepção pode ser encontrada no discurso do procurador-geral da República, para quem "a descentralização não pode ser invocada para negar o direito do cidadão". Essa fala vai de encontro a algumas afirmações feitas durante a audiência. Se o argumento do alto custo gerado pelas demandas judiciais em saúde foi o mais utilizado, podemos dizer que, em seguida, encontramos a defesa de que a maior parte das ações não acerta os seus destinatários. A União diz que é responsabilidade dos estados e 
municípios; os estados acusam os municípios; os municípios culpam os estados. O que está em jogo aqui, portanto, é a ideia de solidariedade entre os entes federativos na garantia do direito à saúde.

Além da primeira premissa, indicada por Tate e Vallinder (1995), e discutida até o momento (referência à Carta Constitucional), pode-se distinguir uma segunda premissa nas oratórias dos participantes da APS: a existência de grupos de pressão que tenham identificado nos tribunais possíveis arenas para a veiculação de seus interesses.

Os representantes de grupos de patologias específicas, que participaram como oradores da AP, são um exemplo típico desses grupos de pressão, figurando como um dos principais defensores da judicialização da saúde. Destacamos os pronunciamentos dos representantes das seguintes instituições: Grupo Hipupiara Integração e Vida, Associação Brasileira de Grupos de Pacientes Reumáticos, Associação Brasileira de Mucopolissacaridoses e Associação Brasileira de Assistência à Mucoviscidose. Esses são grupos de pacientes que encontraram coro às suas demandas apenas nos tribunais judiciais, pois foram excluídos das prioridades do Executivo e não encontraram acolhimento nos trâmites do Legislativo. Nas falas de seus representantes sobressai a lógica pragmática voltada para a dimensão individual da saúde. A defesa dessa dimensão aborda frequentemente questões financeiras e econômicas da área da saúde. O defensor público geral da União, pronunciando-se em favor dos grupos mencionados, afirma que o risco de desestruturação do sistema de saúde não pode ser utilizado como argumento para se negar o direito à vida de alguém. Esse argumento coaduna-se com uma visão mais pragmática, pois se volta para a discussão de um caso concreto e específico.

A fala desses grupos voltou-se exclusivamente para a defesa da dimensão individual do direito à saúde, o que foi ponderado por alguns oradores pela contraposição da face coletiva desse direito. Assim, um orador traz para o debate uma questão que considera problemática no atual estágio da judicialização da saúde: o fato de o Judiciário dar ganho de causa às ações individuais e não às coletivas.

A discussão jurisprudencial sobre o bem jurídico "saúde", na forma peculiar pela qual se desenvolveu entre nós, não enfocou o SUS diretamente, senão tendeu a considerá-lo pelo seu avesso, isto é, pelo cuidado das doenças e, neste, pela busca a assistência farmacêutica. Ou seja, a maior densidade do labor judicial se ateve a apreciar ações, sobretudo individuais, que buscavam os fármacos. Nesse perímetro estrito, é que se apresentam a debate a universalidade, a integralidade de atenção, a igualdade e seu subproduto conceitual, a equidade, e a resolutividade, esteios mestres do Sistema Único de Saúde. É de baixíssima intensidade estatística os volumes das decisões voltadas para políticas sociais e econômicas que visem à redução dos riscos de doenças ou outros agraves de forma coletiva, bem como aqueles que afetam o meio estranho da gestão e o do financiamento público da saúde. Apesar de serem questionados em diversas ações públicas, não há decisão judicial nesse sentido em termos percentuais. A agenda judicial, portanto, é proposta pelo acúmulo de ações e decisões, notadamente disputando drogas prescritas sob os mais variados critérios (Procurador da República). 
Cumpre destacar ainda a posição do procurador-geral da República de que, "embora prevaleça nas ações individuais a dimensão individual do direito à saúde, não se pode automaticamente concluir que elas necessariamente prejudiquem a dimensão social do direito à saúde ou a coletividade". Posição semelhante a esta assume o procurador do Rio de Janeiro, para quem se deve converter este debate do individual para o coletivo:

o que se deve decidir não é se uma pessoa deve merecer o provimento da sua postulação judicial; o que o Judiciário tem que decidir é se todas as pessoas que estão naquela situação merecem ser atendidas, porque, aí, em vez de se atender uma pessoa, cria-se uma política pública para atender àquela necessidade (Procurador do Rio de Janeiro).

A terceira condição da judicialização que merece destaque reúne três das premissas clássicas, pois diz respeito tanto à atuação do Executivo quanto à do Legislativo. O fato de se recorrer ao Judiciário para se ter acesso a medicamentos indica que as políticas desenvolvidas pelo Executivo têm sido falhas. Por outro lado, o Legislativo não vem atuando, por exemplo, sobre as formas de financiamento, nem criando normas para distribuição de medicamentos — principais áreas que vêm propiciando o aumento das demandas judiciais em saúde. Não à toa, nos discursos de grande parte dos oradores, as normas infraconstitucionais estabelecidas pelo Ministério da Saúde são evocadas com status de lei.

Neste cenário, encontramos indícios de que as instituições majoritárias (por exemplo, as Secretarias de Saúde) têm sido incapazes de desenvolver políticas públicas, não conseguindo angariar apoio público suficiente para manter essas políticas. A falta de reconhecimento popular a respeito das políticas implantadas também é um dos fatores que têm fomentado a judicialização. Há uma percepção pragmática de que o acesso aos serviços e insumos de saúde não tem sido garantido pelas políticas oficiais. Busca-se, portanto, essa garantia através do Judiciário.

Além dessa percepção mais pragmática, é possível afirmar que existe também uma posição que assume como inerente certa ineficiência do processo político de decisão concentrado no Executivo. Isto é, determinados grupos passaram a buscar na justiça a garantia de seus direitos à saúde por não acreditarem que seja possível o Executivo, por conta própria — ou até mesmo respondendo às pressões desses grupos - , atender a suas demandas. O pleito via judicial acaba sendo uma forma de driblar o processo político convencional (Taylor, 2007), normalmente mais demorado, pois envolve, além de um procedimento extenso, a construção de acordos, alianças e concessões entre representantes de interesses divergentes, sendo a via judicial, portanto, um atalho eficiente na busca de soluções imediatas.

Um dos casos em que fica evidente a morosidade do processo legislativo diante das diversas demandas sociais - Tate (1995) se refere a uma possível "inércia" legislativa — diz respeito à incorporação tecnológica no SUS. Na AP foram questionados, por diversos grupos, os motivos que levam os gestores a não ampliarem as listas de cobertura do SUS. As explicações aventadas abrangiam problemas relativos aos riscos à segurança do paciente na utilização de tecnologias ainda não aprovadas pelo Ministério da Saúde; ao custo elevado de alguns tratamentos devido 
à preservação dos direitos de patente das indústrias da saúde; e, por fim, às pressões exercidas pelas indústrias para a incorporação de tecnologias ao SUS, sem prejuízos, evidentemente, de seus lucros.

O debate acerca da incorporação tecnológica pelo SUS também é marcado pela intervenção de representantes do setor empresarial. Destaca-se, inicialmente, a postura assumida por um representante da indústria farmacêutica brasileira, que, a fim de defender "o ponto de vista empresarial", isto é, o ponto de vista da indústria farmacêutica nacional, apoia abertamente a atual política do SUS.

Objetivamente, Senhor Presidente, pensamos que, em primeiro lugar, o SUS deva dar cobertura apenas aos medicamentos registrados pela Anvisa no Brasil. Todas as nossas empresas precisam registrar produtos junto à Agência para que tenham atestadas a eficácia e a segurança. Não existe nenhuma razão para que o sistema forneça um produto que não foi aprovado no país. Um produto não registrado no Brasil não está amparado pela nossa legislação. Portanto, a sua comercialização, do ponto de vista empresarial, é concorrência desleal.

É interessante notar, a partir da fala acima, embora não seja possível nos aprofundarmos sobre isso, que é no mínimo imprudente considerarmos os interesses da "indústria farmacêutica" como algo homogêneo. É necessário tratar concretamente a qual indústria está se referindo ao se falar de seus interesses. No caso em exame, podemos perceber um conflito entre interesses econômicos de setores da indústria nacional e da indústria estrangeira. Não podemos ignorar a importância econômica que o SUS representa para diversos segmentos da indústria nacional e internacional. O tipo de política adotada pelo SUS tem um impacto direto no desenvolvimento dessas indústrias, o que justifica seu interesse no debate público sobre a judicialização da saúde no país. Como afirmara Tate (1995:30), "seria um equívoco deixar a impressão de que a judicialização da política se desenvolve de algum modo isolada dos interesses sociais e econômicos que estruturam o sistema político". Essa conexão entre interesses econômicos e o processo de judicialização, que por vezes passa despercebida para a maioria dos pacientes, não deixa, no entanto, de ser notada com apreensão pelos gestores do SUS.

Um posicionamento surgido durante a AP é o de que parte dos problemas causados pela demanda judicial, sobretudo os relativos aos gastos financeiros, decorreria da manutenção das patentes dos medicamentos. O direito de patente constitui-se, portanto, o principal instrumento das indústrias farmacêuticas para garantir seus interesses econômicos. O que agrava esse quadro, no momento da demanda judicial em saúde, é a compra, pelo Estado, em regime de urgência, impossibilitando as negociações de preços, prevalecendo o valor cobrado pelas empresas.

Impulsionados também por essa questão, alguns oradores apresentaram, como solução para driblar os interesses das indústrias de saúde, o fortalecimento da Comissão para Incorporação de Tecnologias no SUS (Citec). Ficou evidente, em algumas falas, a necessidade de uma resposta positiva ou negativa em relação à incorporação de determinada tecnologia. Para o presidente do Conselho Nacional de Secretarias Municipais de Saúde (Conasems), uma siste- 
mática incorporação de tecnologias ao SUS evita "a pressão de produtores e comerciantes de medicamentos, equipamentos, procedimentos, nacionais ou multinacionais, que têm o interesse financeiro envolvido e podem deixá-lo se sobrepor à saúde da população".

A falta de análises rotineiras para a incorporação de novas tecnologias ao SUS cria no juiz, no momento de decidir sobre a concessão de determinado insumo, uma sensação de insegurança. Nesse sentido, o Judiciário tem atuado muito mais no vazio das decisões do SUS do que indo contra os protocolos e diretrizes existentes. Essa constatação leva a uma das premissas apresentadas por Tate e Vallinder (1995): uma postura dos juízes no sentido de aceitarem o desafio de opinar sobre questões políticas.

Conjuntamente com essa constatação, foram feitas diversas críticas em relação à legitimidade e à competência do Poder Judiciário para desempenhar o papel assumido na área da saúde, visando desqualificar assim o fenômeno da judicialização. Em geral, isso foi feito associando essa ideia ao fato de os juízes não terem conhecimento científico suficiente para decidir sobre prescrição de medicamentos, ou, muitas vezes, não terem condições de identificar interesses de empresas e indústrias farmacêuticas por trás de muitos desses pedidos.

\section{Considerações finais}

O que esteve em jogo nesta AP foi, entre outras coisas, a legitimidade ou não do Judiciário para atuar na área da saúde. Talvez exista uma expectativa, certamente ingênua, de alguns gestores de tentar limitar a atuação do Judiciário nessa área, não só pela retração do Poder Judiciário, mas também pela ampliação dos poderes do Executivo. Nesse sentido, destaca-se a resposta de um dos participantes a respeito das diversas propostas de supressão da participação do Judiciário na área da saúde.

O que me preocupa aqui é a dupla exclusão: é a exclusão de quem não recebe nem o medicamento que o protocolo, a lei impõe o fornecimento, e a exclusão de que essa pessoa não poderia, então, buscar o Poder Judiciário, seja por via coletiva, seja por via individual. É dupla exclusão do sistema: ou seja, temos que nos conformar a sermos atendidos na medida do sistema existente e não sermos atendidos, ainda que a lei, os protocolos imponham esse atendimento (Ingo W. Sarlet).

Destaca-se, ainda, a expectativa de que o atual estágio da judicialização da saúde no Brasil tenha um efeito pedagógico sobre os gestores. É visível, para toda a sociedade brasileira, que o investimento no setor saúde tem sido incapaz de atender às demandas mais básicas de toda a população. A judicialização, dessa forma, seria tratada mais como um indicador das condições de saúde do que como um problema em si mesmo.

A APS é um marco importante para este recente fenômeno da judicialização que vive o Brasil. Mesmo porque é o STF quem tem o monopólio de dizer o que é ou não constitucional. A centralidade dessa instituição, no cenário político nacional, pode estar encoberta por opção 
própria do STF. Diversos estudos demonstraram (Da-Ros, 2008; Maranhão, 2003) que o STF tem se mantido fora de temas fundamentais para o governo central, como nos casos de privatização e de política econômica, entre outros. Estudo de Penalva, Diniz e Medeiros (2010) confirma a posição de que matérias que tenham grande interferência da gestão financeira do Estado não obtêm resultados favoráveis do STF. "No processo de judicialização da política assistencial, o argumento orçamentário foi o principal fundamento para a decisão da Corte" (Penalva, Diniz e Medeiros, 2010:65). Contudo, ao contrário disso, o STF tem tido a última palavra em matérias que não causam tanta repercussão nos governos centrais.

Embora o STF tenha dado pareceres favoráveis às demandas judiciais em saúde, isso não significa dizer que essa Corte está adentrando num limite autoimposto de atuação política. Destaca-se que suas discussões e proposições têm se limitado aos casos individuais, reforçando a perspectiva de apropriação individual de um direito que é coletivo.

A APS teve o mérito de evidenciar os conflitos que são próprios da sociedade brasileira: diversas concepções de saúde em disputa. Não é o caso de apontar uma posição vencedora, exceto o crescimento que isto trouxe para a própria sociedade, tanto no que diz respeito aos procedimentos democráticos quanto aos efeitos concretos que a audiência trouxe para a saúde; o mais evidente, a garantia de que o direito à saúde pode ser demandado judicialmente.

\section{Referências}

CAPPELLETTI, Mauro. Juízes legisladores? Porto Alegre: Sergio Antonio Fabris Editor, 1993.

DA-ROS, Luciano. Decretos presidenciais no banco dos réus: análise do controle abstrato de constitucionalidade de medidas provisórias pelo Supremo Tribunal Federal no Brasil (1988-2007). Dissertação (mestrado) - Universidade Federal do Rio Grande do Sul, Rio Grande do Sul, 2008.

GOUVÊA, Marcos M. O direito ao fornecimento estatal de medicamentos. Revista Forense, Rio de Janeiro, v. 370, p. 103-134, 2003.

HIRSCHL, Ran. The new constitutionalism and the judicialization of pure politics worldwide. Fordham Law Review, v. 75, p. 721-754, 2006.

MACHADO, Felipe R. de S. A judicialização da saúde no Brasil: cidadanias e assimetrias. Tese (doutorado) - Instituto de Medicina Social, Universidade do Estado do Rio de Janeiro, Rio de Janeiro, 2010.

MARANHÃO, Tatiana de P.A. Quando o Supremo Tribunal Federal discorda do presidente da República (1988-2001). Dissertação (mestrado) — Universidade de Brasília, Brasília, 2003.

MATTOS, Ruben A. de. A integralidade na prática (ou sobre a prática da integralidade). Cadernos de Saúde Pública, Rio de Janeiro, v. 20, n. 5, p. 1411-1416, 2004.

OLIVEIRA, Vanessa E. de. Poder Judiciário: árbitro dos conflitos constitucionais entre Estados e União. Lua Nova, São Paulo, n. 78, p. 223-250, 2009. 
PENALVA, Janaína; DINIZ, Debora; MEDEIROS, Marcelo. O benefício de prestação continuada no Supremo Tribunal Federal. Sociedade e Estado, v. 25, n. 1, p. 53-70, 2010.

PERELMAN, Chaim; OLBRECHTS-TYTECA, Lucie. Tratado da argumentação: a nova retórica. São Paulo: Martins Fontes, 1996.

TATE, Chester. N. Why the expansion of Judicial Power? In: TATE, Chester N.; VALLINDER, Torbjörn (Org.). The global expansion of Judicial Power. Nova York, Londres: New York University Press, 1995. p. 27-37.

TATE, Chester N.; VALLINDER, Torbjörn (Org.). The global expansion of Judicial Power. Nova York; Londres: New York University Press, 1995.

TAYLOR, Matthew. M. O Judiciário e as políticas públicas no Brasil. Dados, Rio de Janeiro, v. 50, n. 2, p. 229-257, 2007.

TREVISAN, Leonardo. Das pressões às ousadias: o confronto entre a descentralização tutelada e a gestão em rede no SUS. Revista de Administração Pública, Rio de Janeiro, v. 41, n. 2, p. 237-254, 2007.

TOCQUEVILLE, Alexis de. A democracia na América. Belo Horizonte: Itatiaia, 1987.

VENTURA, Mirian et al. Judicialização da saúde, acesso à justiça e a efetividade do direito à saúde. Physis, v. 20, n. 1, p. 77-100, 2010. On-line.

VIANNA, Luiz W. et al. A judicialização da política e das relações sociais no Brasil. Rio de Janeiro: Revan, 1999.

WEBER, Max. Sociologia. Organização de Gabriel Cohn. São Paulo: Ática, 2004. (Grandes Cientistas Sociais).

Felipe Rangel de Souza Machado é pesquisador em saúde pública da Fundação Oswaldo Cruz na Escola Politécnica de Saúde Joaquim Venâncio (EPSJV/Fiocruz). E-mail: felipemachado@fiocruz.br.

Sulamis Dain é professora titular do Instituto de Medicina Social da Universidade do Estado do Rio de Janeiro (IMS/Uerj).E-mail: sulamis@uol.com.br. 